\title{
The Management of .22 Caliber Gunshot Wounds of the Brain: A Review of 49 Cases
}

\author{
L. Suddaby, B. Weir and C. Forsyth
}

\begin{abstract}
We analyzed the charts and CT scans of 49 cases of civilian .22 caliber gunshot wounds of the brain admitted to the University of Alberta and Royal Alexandra Hospitals between 1975 and 1985. The average age of the patients was 30 years, $88 \%$ were males, $88 \%$ were suicide attempts. There were no deaths among patients with an initial coma score above 12 whereas the mortality rate was $85 \%$ for those admitted with a score of 7 or less. All those with fixed pupils on admission died. The overall mortality rate of $61 \%$ is comparable to that of other series of civilian gunshot wounds including those in which more aggressive surgical management was undertaken. We recommend that no treatment be given those cases with an admission coma score of 3 and/or fixed pupils and that simple scalp wound debridement be employed with those having a coma score of 7 or less. Tract exploration and retrieval of bullet fragments is not indicated, as retained fragments carry a very low incidence of complications (e.g. abscess formation). In patients in good condition ( $G C S \geqslant 12$ ) the management of intracranial hematomas should be independent of their etiology and approached aggressively.
\end{abstract}

RÉSUMÉ: Conduite à tenir dans les cas de blessure du cerveau par balle de calibre 22: revue de $\mathbf{4 9}$ cas. Nous avons analysé les dossiers et les tomographies axiales assistées par ordinateur de 49 cas de blessures du cerveau par balle de calibre 22 chez des civils admis à l'Hôpital “University of Alberta” et à l'Hôpital Royal Alexandra entre 1975 et 1985. L'âge moyen des patients était de 30 ans, $88 \%$ étaient des hommes, $88 \%$ des blessures étaient le résultat de tentatives de suicide. Il n'y a pas eu de décès parmi les patients dont l'indice de coma était au-dessus de 12, alors que le taux de mortalité était de $85 \%$ pour ceux qui étaient admis avec un indice de 7 ou moins. Tous ceux dont les pupilles étaients fixes à l'admission sont décédes. Le taux de mortalité globale de $61 \%$ observé est comparable à celui d'autres séries de blessures par balles chez des civils incluant celles dans lesquelles un traitement chirurgical agressif était entrepris. Nous recommandons qu'aucun traitement ne soit donné aux patients dont l'indice de coma est de 3 à l'admission et/ou des pupilles fixes, et qu'un simple débridement de la plaie du cuir chevelu soit fait chez ceux qui ont un indice de coma de 7 ou moins. Il n'est pas indiqué de procéder à l'exploration du trajet de la balle ou à la récupération des fragments, les fragments restants ayant un taux de complications très bas (i.e. formation d'abcès). Chez les patients en bon état (indice de 12 ou plus), le traitement des hématomes intracrânines doit être indépendent de leur étiologie et doit être abordé de façon agressive.

Can. J. Neurol. Sci. 1987; 14:268-272

Prior to World War I penetrating head injury focused almost solely on the skin and the skull. It was during this war that significant advances in the care of these injuries was pioneered by Harvey Cushing who advocated the value of early definitive surgery, focusing on removal of infected bone fragments and clot, coupled with watertight dural closure. Advances since that time have largely centered on improved transport of patients, effective antibiotic therapy and general perioperative management. 1 2.3.4.5

Most of the recent literature has been based on military experience or civil unrest. Few studies have dealt with the low velocity craniocerebral bullet injury that more commonly presents to the physician in civilian practice. 


\section{MATERIAL AND METHOdS}

A retrospective analysis of 49 patients admitted with a .22 caliber gunshot wound of the brain during the years 1975 to 1985 at the University of Alberta and Royal Alexandra Hospitals was conducted. We excluded cases of low velocity which were of larger caliber or cases in which the caliber was uncertain. All cases with a GCS $\leqslant 14$ were treated with Mannitol as initial or subsequent therapy, but steroids were not used.

\section{RESULTS AND COMMENTS}

The age range of patients was from 8 to 92 years with an average age of 30.4 years. Forty three patients were male $(88 \%)$ and six (12\%) were female. Clinical assessments were made on the basis of the Glasgow Coma Scale on admission and the Glasgow Outcome Scale on discharge. ${ }^{6}$

In terms of the site of entry, the frontal area was involved most frequently (47\%) followed by the temporal and parietal areas. Although there is a suggestion that temporal sites are more lethal, this was not statistically significant.

The coma score on admission was compared to both mortality and outcome. In terms of mortality, there were no deaths in the patient group with a Glasgow Coma Score of above 12, whereas in the groups with a coma score below 7 there were 28 deaths (Table 1). These findings were statistically significant $(p<0.001)$. The overall mortality rate was $61 \%$ for this series. Suicide was the most common method of injury (Table 2). Of

\begin{tabular}{ccl}
\hline \multicolumn{4}{l}{ Table la: Coma scale on admission vs mortality } & \\
\hline \hline & Survivors & Dead \\
\hline${ }^{*}$ GCS $12-15$ & 10 & 0 \\
$8-11$ & 4 & 2 \\
$\leqslant 7$ & 4 & 28 \\
TOTAL & $19(39 \%)$ & $30(61 \%)$ \\
\hline
\end{tabular}

$\mathrm{p}<0.001$

* Glasgow Coma Scale

\begin{tabular}{ccc}
\hline \multicolumn{3}{l}{ Table 1b: Coma scale on admission vs outcome } \\
\hline \hline & Good - Moderate & Poor - Vegetative - Dead \\
\hline${ }^{*} \mathrm{GCS} \geqslant 8$ & 14 & 2 \\
$\leqslant 7$ & 4 & 29 \\
TOTAL & $18(37 \%)$ & $31(63 \%)$ \\
\hline
\end{tabular}

$\mathrm{p}<0.001$

* Glasgow Coma Scale

\begin{tabular}{lc}
\hline Table 2: Nature of injury & \\
\hline \hline Suicide & $43(88 \%)$ \\
Homicide & $1(2 \%)$ \\
Accidental & $4(8 \%)$ \\
Uncertain & $1(2 \%)$ \\
\hline
\end{tabular}

considerable interest was that the site of entry showed no correlation with outcome.

In terms of age versus outcome two age groups were compared; those over 40 and those less than 40 . These age categories were subdivided into two subgroups: the first was comprised of those patients with either good or moderate outcome and the second those whose outcome was either poor, vegetative or dead. These comparisons suggested a slightly better outcome for persons younger than 40 years ( $38 \%$ good - moderate outcome), than those persons of age greater than 40 years $(33 \%$ good moderate outcome). These differences were not statistically significant but suggested a trend towards a better outcome in younger patients (Table 3 ). Two patients were over 80 years of age and neither survived (Table 3 ).

Comparison of blood pressure on admission versus mortality showed normotensive patients had a slightly lower mortality (Table 4) but these differences were not statistically significant.

Pupillary responses were useful prognostically. Equal and reacting pupils indicated the best chance of survival and a good outcome. Unequal pupils did not appear to significantly alter outcome as 11 of 16 patients with equal pupils had a good or moderate outcome $(68 \%)$ while 7 of 9 patients with unequal pupils had a good or moderate outcome (77\%). Fixed dilated or fixed mid position pupils uniformly preceded death. These findings were statistically significant $(p<0.001)$ (Table 5).

The number of brain lobes injured as judged by computerized tomographic (CT) scan correlated with the outcome. As the number of lobes injured increased, the chance of a good outcome decreased. Persons sustaining injury to a single lobe had the best chance of a good or moderate outcome $(p=.11)$ (Table 6). Internal ricochet can increase the number of lobes involved (Figure 1).

\begin{tabular}{lrrrr}
\hline Table 3a: Age vs mortality & & & & \\
\hline \hline & \multicolumn{3}{c}{ Survivors } & \multicolumn{2}{c}{ Dead } \\
\hline $0-19$ years & 5 & $(31 \%)$ & 11 & $(69 \%)$ \\
$20-39$ years & 11 & $(45 \%)$ & 13 & $(54 \%)$ \\
$40-59$ years & 2 & $(33 \%)$ & 4 & $(67 \%)$ \\
$60-79$ years & $1(100 \%)$ & 0 & $(0 \%)$ \\
$80+$ years & 0 & $(0 \%)$ & $2(100 \%)$ \\
\hline
\end{tabular}

$p=0.99$ no significant difference across ages

\begin{tabular}{lcc}
\hline Table 3b: Age vs outcome & \\
\hline \hline & Good - Moderate & Poor - Vegetative - Dead \\
\hline$<40$ years & $15(38 \%)$ & $25(63 \%)$ \\
$>40$ years & $3(33 \%)$ & $6(67 \%)$ \\
\hline
\end{tabular}

$\mathrm{p}=0.88$

\begin{tabular}{lrr}
\hline \multicolumn{4}{l}{ Table 4: Blood pressure on admission vs mortality } & \\
\hline \hline Systolic BP in mmHg & Survivors & \multicolumn{1}{c}{ Dead } \\
\hline$>150$ & $7(39 \%)$ & $11(61 \%)$ \\
$90-150$ & $11(44 \%)$ & $25(52 \%)$ \\
$<90$ & $1(20 \%)$ & $4(80 \%)$ \\
\hline
\end{tabular}

* One blood pressure was not recorded on admission $\mathrm{p}=0.6$ 
The presence or absence of a midline shift on CT in relation to outcome was studied. The results suggest a trend for cases with a midline shift to have a poorer outcome. As well, comparisons of the presence or absence of basal cisterns on CT suggested a similar trend with absent basal cisterns having a poorer outcome, although these differences were not statistically significant (Table 7).

Of the patients entered into the study six underwent emergency craniotomy for evacuation of an intracranial hematoma. Four patients underwent surgery for significant intracerebral hematomas. Two of these patients subsequently died, one had a moderate outcome and one a good outcome. Two patients underwent craniotomy for subdural hematoma, and both subsequently died. One patient underwent local wound debridement in the operating room, with the remainder of patients receiving local superficial wound care in the emergency room prior to admission to ICU or general ward. An example of bleeding along a bullet path is given in Figure 2.

It is of interest that there was only one case of brain abscess encountered in this series despite the fact that all surviving cases carry retained metal fragments (Figure 3 ). The most common complication was cerebrospinal fluid leak which developed in five cases. In addition, single cases of meningitis, hydrocephalus, and late epilepsy were encountered. The total complication rate was $16 \%$.

\section{Discussion}

The problem of penetrating brain injury has spanned centuries. Unfortunately, the evolution of the weapons designed to inflict such injuries has occurred more rapidly than the means avail-

\begin{tabular}{lcc}
\hline \multicolumn{3}{l}{ Table 5: Pupillary size on admission vs outcome } \\
\hline \hline & Good - Moderate & Poor - Vegetative - Dead \\
\hline $\begin{array}{l}\text { Equal/Reacting } \\
\text { and Unequal }\end{array}$ & $18(72 \%)$ & $7(28 \%)$ \\
$\begin{array}{l}\text { Fixed/Dilated and } \\
\text { Fixed/Mid Position }\end{array}$ & $0(0 \%)$ & $22(100 \%)$ \\
\hline
\end{tabular}

$\mathrm{p}<0.001$

\begin{tabular}{lcc}
\hline \multicolumn{3}{l}{ Table 6: Number of lobes injured vs mortality } \\
\hline \hline Number of lobes & Good - Moderate & Poor - Vegetative - Dead \\
\hline 1 & 11 & 8 \\
$\geqslant 2$ & 8 & 19 \\
\hline
\end{tabular}

$p=0.11$ no statistical difference

\begin{tabular}{lcc}
\hline \multicolumn{3}{l}{ Table 7: Presence/absence of midline shift vs outcome } \\
\hline \hline & Good - Moderate & Poor - Vegetative - Dead \\
\hline Present & 12 & 9 \\
Absent & 3 & 2 \\
\hline
\end{tabular}

There is no statistical difference, however, the numbers sampled are low. able to treat them. In the civilian setting, retained fragments do not appear to pose sufficient risk of infection or abscess to warrant aggressive removal of the fragments which are not readily accessible. . $^{7.9 .10 .11 .12,13.14 .15 .16}$ Fragments are often widely dispersed throughout the brain because of scatter on impact and internal ricochet. This is relatively more common in

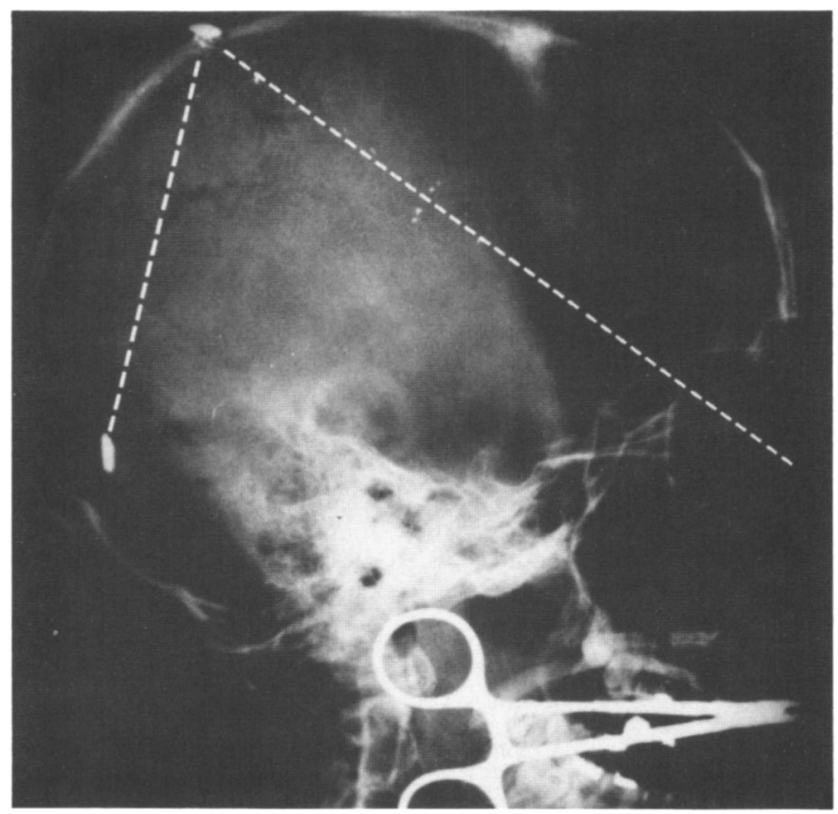

Figure I - Illustrates how internal ricochet increases the length of the bullet path and potentially the number of lobes involved.

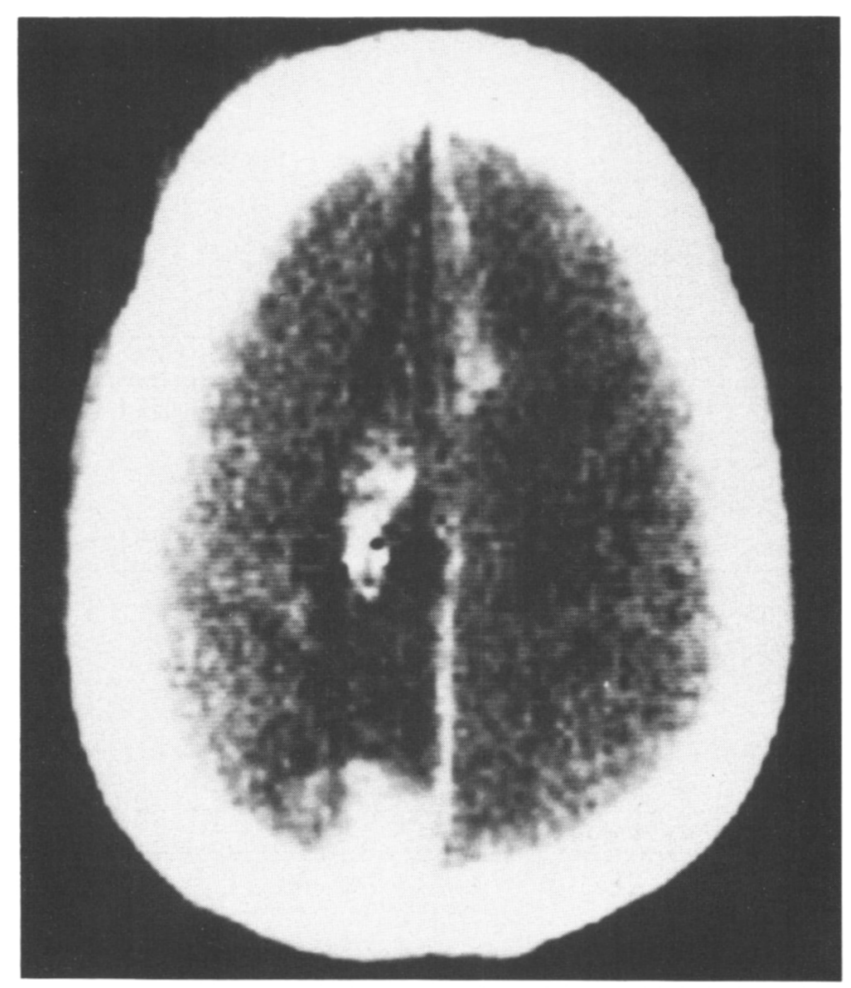

Figure $2-C T$ scan illustrates the multiple hematomas along the anteroposterior intracranial trajectory of a .22 caliber bullet. 
lower velocity .22 caliber bullet injury than with higher velocities and tends to increase the total amount of brain damaged. The CT scan is a useful modality for the rapid assessment of the type and magnitude of cerebral disruption.

Delayed tract exploration might be an option for an abscess developing some time after the injury. We would probably also consider CT-guided aspiration at that point.

Useful prognostic factors included level of consciousness and pupillary responses. Admitting blood pressure, evidence of midline shift on CT scan, evidence of obliteration of the basal cisterns on CT scan, seemed useful adjuvant parameters but did not carry the same level of statistical significance in regard to their effect on outcome.

Our current management policy based on this review is to treat entrance wounds with local debridement if any treatment is undertaken. Fragments are very seldom sought and removed, unless readily accessible. Antibiotic therapy is not administered prophylactically. In our opinion no firm recommendation can be made regarding prophylactic anticonvulsant therapy. General supportive therapy, including mechanical ventilation, is undertaken in appropriate cases. Heroic supportive measures are probably not indicated in elderly patients with signs of advanced deterioration such as fixed pupils, very low coma scores, massive clots and absent basal cisterns.

A pathological study of fatal .22 caliber injuries revealed that of 12 cases, $83 \%$ had the bullet enter the skull and not exit it, the permanent cavities ranged between 5.4 and $35.8 \mathrm{cc}$, $75 \%$ had contusions or uncal/tonsillar herniation, $50 \%$ had bone chips palpated in the cavities, ricochet was found in only 1 case. ${ }^{12}$ Depending on the type of .22 caliber weapon, muzzle velocities range from 861 to $1250 \mathrm{ft} / \mathrm{sec}$ and muzzle energies from 48 to 139 $\mathrm{ft}-\mathrm{lb}$. The volume of the damaged cavity was not directly related to bullet caliber in these low velocity civilian injuries. Temporary cavity formation is much less extensive than with high velocity military injuries. Bone chips always originate at the entrance cavity. Cerebral edema was considered to develop within minutes of wounding.

Between 1961 and 1969, 154 civilian craniocerebral bullet injuries were treated at two hospitals in Cleveland and Chicago. Of the total, $32 \%$ had no cerebral penetration and did well. Of $45 \%$ with cerebral penetration $90 \%$ survived, all but $10 \%$ being well. Of the total, $23 \%$ of cases died. This appears to indicate that there must have been considerable preinstitutional selection. The only case to develop a brain abscess had frontal sinus involvement. $26 \%$ of 35 survivors followed from one month to 4 years had seizures. The investigators advocated a conservative surgical approach with superficial debridement in all but hopeless cases and removal of the bullet only when "eminently accessible", thereby differentiating the surgical approach to civilian wounds from those occurring during warfare.

In Finland, 123 civilians with cranial gunshot wounds were studied between 1968 and $1977 .{ }^{14}$ Sixteen percent were dead on arrival and $8 \%$ had no cerebral penetration. Cerebral gunshot wounds made up $2 \%$ of all head injuries. Eighty-seven percent were suicides. In $51 \%$ missile wounds were simply closed, $18 \%$ had craniotomy and debridement of necrotic tissue or hematoma removal. Using the Glasgow outcome scale at an average of 57 months post injury, $79 \%$ were dead, $8 \%$ severely disabled, $3 \%$ moderately disabled and $10 \%$ made a good recovery. The causes of wounds were accidents in $4 \%$, assault $9 \%$ and suicide $87 \%$. Of interest, $9 \%$ of suicide cases made a good recovery but for the 64 such cases who were unconscious on admission, only 2 (3\%) survived and both were severely disabled. All 29 cases unresponsive to pain on admission died. Seventy-nine percent with missile tracts crossing both mid-coronal and mid-sagittal planes died. Only 1 of 22 cases who were older than 60 did not die. The overall mortality of cases seen by neurosurgeons was $79 \%$, however there were 320 deaths from craniocerebral gunshot wounds in their catchment area over the time of their review hence the true mortality of civilian cerebral gunshot wounds was estimated to be $97 \%$ !

In a later series of 56 cases of civilian gunshot wounds in France, the mortality was $53 \% .{ }^{15}$ Their surgical approach was to debride entrance and exit sites with dural graft being obtained, if necessary, from adjacent pericranium or temporalis fascia. They made no attempt to retrieve missile fragments unless they were immediately accessible. Fifteen patients admitted alert but with no neurologic findings had a $13 \%$ mortality, 11 drowsy cases $-27 \%, 14$ comatose without brain stem signs $-64 \%, 16$ comatose with brain stem signs - $100 \%$. Mortality by course of missile tract was as follows: one lobe $-20 \%$, crossed midsagittal plane $-50 \%$, crossed mid-coronal plane $-80 \%$, crossed both planes - 92\%. The most common CT features were: band shaped intracerebral hematoma $-79 \%$, extracerebral pneumocephalus $-71 \%$, significant subarachnoid hemorrhage $-59 \%$, intraventricular hemorrhage $-48 \%$, intracerebral pneumocephalus $-43 \%$, diffuse cerebral edema $-38 \%$, extensive intracerebral hematoma - 23\%, extensive extracerebral hematoma - $13 \%$.

At the Tennessee Health Sciences Center, 76 civilian gunshot wounds were treated in the 20 month period ending in $1985 .{ }^{16}$ Overall there was a $62 \%$ mortality rate. Patients with a GCS of 3 invariably died, with or without surgery and the

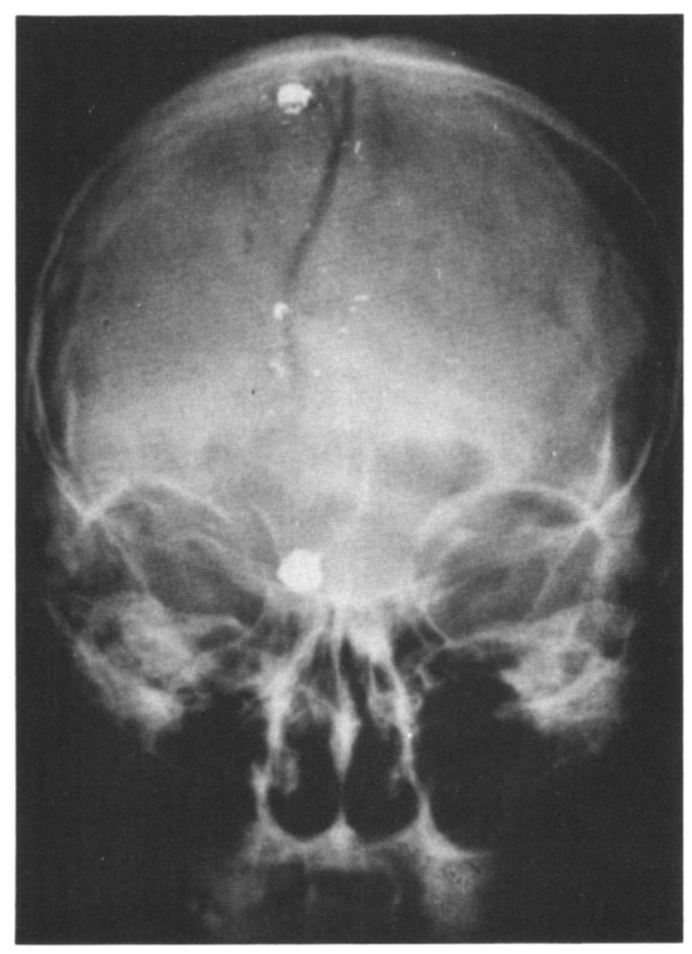

Figure 3 - Illustrates the mumerous retained fragments which are commonly seen following low velocity, small caliber gunshot wounds 
presence of intracranial hematomas, ventricular injury or bihemispheric wounding worsened the prognosis. Eighty-six percent of the 35 suicides were in whites and $78 \%$ of the 41 homicides were in blacks. Of 9 operated cases who subsequently died Glasgow Coma Scores were 3 in 2 cases, 4 in 5 cases and 5 or more in 2 cases. All patients received prophylactic intravenous antibiotics, 2 developed meningitis. All patients received loading doses of phenytoin and 3 had seizures at some point. If ventricular injury occurred $90 \%$ had a poor outcome. Their management approach was to explore the wound; remove intracranial hematomas, depressed or in-driven bone fragments, hair and foreign material; debride necrosed brain and remove bullet fragments only when accessible and not requiring an approach through uninjured brain; and meticulously close dura. Despite this more surgically oriented approach than ours, the mortality and infection rates were virtually identical. They did however have no cases of CSF leaks while there were 5 in our series. The incidence of seizures did not appear to be significantly different although we did not employ routine anticonvulsants.

Since great advances in the treatment of these injuries seem unlikely, their prevention would appear to be the most logical and potentially rewarding endeavor.

\section{Conclusions}

1. Small caliber civilian gunshot wounds of the brain may be treated with conservative measures if the patient has a low initial Glasgow Coma Score (3) and/or fixed pupils. At higher grades the status of other prognostic factors should influence the nature of surgery undertaken.

2. If initial surgery is performed, it may be restricted to local debridement of scalp wounds or removal of any life-threatening hematoma and dural closure.

3. Delayed complications such as rhinorrhea, abscess, meningitis or seizures should be treated if and when they arise if the condition of the patient warrants intervention.

\section{ACKNOWLEDGEMENT}

The authors wish to thank Kelly Walker and Arlene MacLean for clerical assistance.

\section{REFERENCES}

1. Byrnes DP, Crockard HA, Gordon DS, et al. Penetrating craniocerebral missile injuries in the civil disturbances in Northern Ireland. Br J Surg 1974; 61: 169-176.

2. Crockard HA. Bullet injuries of the brain. Ann R Coll Surg Engl 1974; 55: 111-123.

3. Gurdjian ES. The treatment of penetrating wounds of the brain sustained in warfare: a historical review. J Neurosurg 1974; 39 : 157-167.

4. Hammon WM. Analysis of 2187 consecutive penetrating wounds of the brain from Vietnam. J Neurosurg 1971; 34: 127-131.

5. Small JM, Turner EA. A surgical experience of 1200 cases of penetrating brain wounds in battle, N.W. Europe, 1944-1945. Br J Surg (War Suppl) 1947; 1: 62-74.

6. Jennett B, Teasdale G. Management of Head Injuries. Philadelphia: FA Davis Co., 1981.

7. Bakay L. Missile injuries of the brain. NY State J Med 1982; March: 313-319.

8. Goodman JM, Kalsbeck J. Outcome of self inflicted gunshot wounds of the head. J Trauma 1965; 5: 636-642.

9. Haddad FS. Nature and management of penetrating head injuries during the Civil War in Lebanon. Can J Surg 1978; 21: 233-238.

10. Hubschman NO, Shapiro K. Baden M, et al. Craniocerebral gunshot injuries in civilian practice - prognostic criteria and surgical management: experience with 82 cases. J Trauma 1979; 19: 6-12.

11. Yashon D, Jane JA, Martonffy D, et al. Management of civilian craniocerebral bullet injuries. Amer Surg 1972; 38: 346-351.

12. Kirkpatrick JB, DiMaio V. Civilian gunshot wounds of the brain. J Neurosurg 1978; 49: 185-198.

13. Raimondi AD, Samuelson GH. Craniocerebral gunshot wounds in civilian practice. J Neurosurg 1970; 32: 647-653.

14. Hernesniemi J. Penetrating craniocerebral gunshot wounds in civilians. Acta Neurochir (Wien) 1979; 49: 199-205.

15. Shoung HM, Sichez JP, Pertuiset B. The early prognosis of craniocerebral gunshot wounds in civilian practice as an aid to the choice of treatment. A series of 56 cases studied by computerized tomography. Acta Neurochir 1985; 74: 27-30.

16. Clark WC, Muhlbauer MS, Watridge CB, et al. Analysis of 76 civilian craniocerebral gunshot wounds. J Neurosurg 1986; 65: 9-14. 